\title{
Retinopathy of prematurity in a controlled trial of prophylactic surfactant treatment
}

\author{
P M Pennefather, W Tin, M P Clarke, S Fritz, N P Strong
}

\begin{abstract}
Aims-To investigate the incidence of acute and cicatricial retinopathy of prematurity (ROP) in a cohort of premature neonates entered into a randomised, multicentre trial of prophylactic exogenous surfactant for respiratory distress syndrome (RDS) compared with controls receiving surfactant only if severe $R D S$ developed.

Methods-The incidence of acute and cicatricial ROP was assessed in 304 neonates born at less than 30 weeks' gestation in a geographically defined population of approximately three million.

Results-There was a trend towards improved survival in the group receiving prophylactic surfactant with 102/151 $(67 \cdot 5 \%)$ surviving compared with $82 / 141$ controls $(58 \cdot 2 \%, p=0 \cdot 12)$. The prophylactic surfactant group would be expected to have an increased risk of ROP due to improved survival, particularly of the most premature infants. However, there was no statistically significant difference in the incidence of acute ROP between the two groups and the incidence of cicatricial ROP was lower in the group receiving prophylactic surfactant (4/100 survivors, $4.0 \%$ ) compared with neonates receiving rescue surfactant as required $(6 / 81,7 \cdot 4 \%)$. This difference did not reach statistical significance $(p=0 \cdot 35)$.

Conclusion-The trend for a lower incidence of cicatricial ROP in those neonates treated with prophylactic surfactant compared with the rescue surfactant group, despite improved survival, suggests that the use of prophylactic surfactant also had a beneficial effect on the development of cicatricial ROP.

(Br f Ophthalmol 1996; 80: 420-424)
\end{abstract}

Victoria Infirmary,

Newcastle upon Tyne

P M Pennefather

M P Clarke

N P Strong

Department of

Paediatrics, Royal

Victoria Infirmary,

Newcastle upon Tyne

W Tin

Regional Maternity Survey Office,

Newcastle upon Tyne

$S$ Fritz

Correspondence to: Mrs P M Pennefather, Department of

Ophthalmology, Royal

Liverpool University

Hospital NHS Trust, Presco

Street, Liverpool L7 8XP

Accepted for publication

7 February 1996

The present epidemic of retinopathy of prematurity (ROP) is attributed to the increased survival of very premature infants. ${ }^{1}$ The survival of very premature neonates has been significantly improved by the use of exogenous surfactant to treat respiratory distress syndrome (RDS). ${ }^{2}$ RDS is due to deficiency of surfactant which is a complex mixture of phospholipids and proteins, produced in the lungs, which reduces the surface tension and so prevents alveolar collapse. Very premature babies treated with surfactant for RDS have a marked improvement in morbidity as well as mortality. ${ }^{3}$

The aetiology of ROP is uncertain. One important factor is gestational age which is inversely related to the incidence of ROP. ${ }^{4-7}$ If gestational age were the sole factor influencing the incidence of ROP then one would expect that the increased survival due to surfactant use would result in an increased incidence of ROP. On the other hand, if respiratory health and homeostasis are also significant determinants of ROP development, then the use of surfactant would be expected to reduce the gestational age-adjusted incidence of ROP. The effect of surfactant upon the overall incidence of ROP would then be determined by the balance of these two opposing effects.

More recently, exogenous surfactant has been used prophylactically in those neonates most at risk of developing RDS. During 1990 and 1991 a multicentre, randomised controlled trial (OSIRIS) compared neonates who received prophylactic surfactant within 2 hours of birth with a control group of neonates who received surfactant treatment only if they developed severe RDS ('rescue' treatment). ${ }^{8}$ This trial studied 2690 neonates and demonstrated that prophylactic surfactant markedly improved morbidity and mortality with a $16 \%$ decrease in death or chronic oxygen dependence at term. The markedly improved survival of premature neonates treated prophylactically with surfactant means that it would now be unethical to perform a prospective randomised trial of prophylactic surfactant. However, the neonates in the OSIRIS trial comprise a suitably randomised cohort, the survivors of which are available for examination.

This paper presents the results of examination of a regionally defined subset of the neonates in the OSIRIS trial, undertaken to determine the effect of prophylactic surfactant administration upon the incidence of ROP in very premature neonates.

\section{Methods}

The details of the controlled trial of prophy-

lactic surfactant are published. ${ }^{8}$ In summary, all neonates born at less than 30 weeks' gestation were eligible for inclusion in the OSIRIS trial if the following criteria were met: (1) already intubated to receive respiratory support; (2) no congenital abnormality; (3) parental consent had been given; and (4) randomised before 2 hours old.

Patients were randomised by the Oxford clinical trials service into prophylactic and rescue surfactant groups, with optimum matching for: (1) gestational age, (2) sex, (3) hospital delivered, (4) single/multiple pregnancy, (5) prenatal dexamethasone.

For ethical reasons it was not possible to design a trial in which one group of neonates 
was denied surfactant therapy. Instead the neonates were allocated randomly to either prophylactic or rescue surfactant groups.

PROPHYLACTIC SURFACTANT GROUP

Patients randomised to this group received prophylactic synthetic surfactant (Exosurf) $5 \mathrm{ml} / \mathrm{kg}$ as a bolus within 2 hours of birth with a further dose 12 hours later.

\section{RESCUE SURFACTANT GROUP}

These neonates received the same surfactant treatment only if clinical RDS developed with an arterial/alveolar oxygen partial pressure (a/A) ratio of $<0 \cdot 22$.

Within both prophylactic and rescue groups there was further randomisation of neonates to receive only two doses of surfactant (as described above) or to receive a further two doses if RDS failed to resolve after the first two doses. The multicentre trial ${ }^{7}$ showed no difference in outcome for the two and four bolus subgroups in either the prophylactic or rescue surfactant groups. These subgroups have therefore been combined for analysis.

\section{RETROSPECTIVE REVIEW OF NEONATAL RECORDS}

Neonatal records were reviewed for the results of screening for acute ROP and treatment by cryotherapy. Screening for acute ROP had been performed in individual neonatal units by local ophthalmologists who were masked to the randomisation group and treatment with surfactant. Pupil dilatation with phenylephrine $2.5 \%$ and cyclopentolate $0.5 \%$ was followed by indirect ophthalmoscopy generally using a speculum and indentor to rotate the eye. Findings were documented in accordance with the international classification of $\operatorname{ROP}^{9}$ namely, stage 1: demarcation line; stage 2: ridge; stage 3: extraretinal fibrovascular proliferation; stage 4: partial retinal detachment; and stage 5: retinal detachment. Threshold disease was defined as at least 5 contiguous clock hours or 8 cumulative hours of stage 3 ROP in zone 1 or 2 in the presence of 'plus' disease (dilatation and tortuosity of the posterior retinal vessels).

\section{EXAMINATION OF CHILDREN AT 2 YEARS}

All neonates surviving until 2 years old were reviewed by one ophthalmologist who was masked to gestational age, neonatal events, whether the child had been allocated to the prophylactic or rescue group, and the results of retrospective review of the notes.

Examination included visual acuity and cover test. Topical cyclopentolate $1 \%$ was instilled 20 minutes before refraction and funduscopy. Particular note was made of as much of the peripheral retina as possible and of the architecture of the posterior pole vessels to identify any minor tractional changes of cicatricial ROP. Additional information was gained from the child's notes when examination under anaesthetic had been performed.

Statistical analysis was by $\chi^{2}$, Fisher's exact test, and two sample $t$ test.

\section{Results}

In the multicentre OSIRIS trial, ${ }^{8}$ prophylactic surfactant improved survival from $70 \%$ to $73.3 \%(p=0.057)$. There was also improved morbidity as shown by $32 \%$ fewer pneumothoraces (absolute difference $-5 \cdot 3 \%, 95 \%$ confidence interval $-8 \cdot 0 \%$ to $-2 \cdot 7 \%$ ) and $22 \%$ fewer other pulmonary air leaks. The children in this study represent $184 / 2690$ $(6.8 \%)$ of the neonates in the OSIRIS trial. There was no significant difference between the two groups at randomisation (Table 1). The two groups showed the same trends of improved mortality and morbidity as the OSIRIS trial, although the smaller numbers make the results not statistically significant. Thus, survival until 2 years old was better in the group receiving prophylactic surfactant, with 102 of $151(67.5 \%)$ surviving compared with 82 of $141(58 \cdot 2 \%, \mathrm{p}=0 \cdot 17$, Table 2$)$. There was a non-significant improvement in morbidity in those receiving prophylactic surfactant: the mean time on the ventilator was reduced from $17 \cdot 8$ days to $15 \cdot 1$ days $(p=0 \cdot 31)$ and there were fewer neonates with pneumothoraces requiring drainage $(5.9 \%$ compared with $9 \cdot 8 \%, p=0.41$, Table 2)

One of the authors reviewed 181 of 184 survivors at approximately 2 years old. Cicatricial ROP occurred in 10 children, ranging from straightening of arcade vessels in association with high myopia to open funnel detachments (Table 3). The incidence of cicatricial ROP was lower in the group receiving prophylactic surfactant $(4 / 100$ survivors, $4 \cdot 0 \%)$ compared with those receiving rescue surfactant as required ( $6 / 81$ survivors, $7 \cdot 4 \%$ ) but this difference was not statistically significant $(p=0 \cdot 35)$. One patient with cicatricial ROP in each group had not received cryotherapy.

The survival and incidence of cicatricial ROP according to gestational age for the two

Table 1 Characteristics of neonates randomised to receive prophylactic surfactant compared with controls receiving rescue surfactant

\begin{tabular}{lccc}
\hline & \multicolumn{1}{c}{$\begin{array}{c}\text { Prophylactic surfactant } \\
(n=151)\end{array}$} & $\begin{array}{l}\text { Rescue surfactant } \\
(n=141)\end{array}$ & $p$ Value \\
\hline Gestational age (weeks) & $27 \cdot 18$ & $27 \cdot 31$ & $0 \cdot 55$ \\
Number (\%) of males & $86(57 \cdot 0)$ & $88(62 \cdot 4)$ & $0 \cdot 40$ \\
Number (\%) of neonates in multiple births & $38(25 \cdot 2)$ & $26(18 \cdot 4)$ & $0 \cdot 20$ \\
Number (\%) receiving antenatal maternal dexamethasone & $24(15 \cdot 9)$ & $16(11 \cdot 3)$ & $0 \cdot 31$ \\
Number (\%) of neonates with a pneumothorax requiring drainage & $19(12 \cdot 6)$ & $27(19 \cdot 1)$ & $0 \cdot 15$ \\
Number (\%) born in teaching hospital & $108(71 \cdot 5)$ & $109(77 \cdot 3)$ & $0 \cdot 29$ \\
\hline
\end{tabular}


Table 2 Characteristics of surviving neonates randomised to receive prophylactic surfactant compared with controls receiving rescue surfactant

\begin{tabular}{lccc}
\hline & Prophylactic surfactant & Rescue surfactant & $p$ Value \\
\hline Number surviving (\%) & $102(67 \cdot 5)$ & $82(58 \cdot 2)$ \\
Gestational age (weeks) & $27 \cdot 76$ & $27 \cdot 80$ & \\
Number (\%) of males & $56(54 \cdot 9)$ & $54(65 \cdot 9)$ & $0 \cdot 86$ \\
Number (\%) of neonates in multiple births & $26(25 \cdot 5)$ & $14(17 \cdot 1)$ & $0 \cdot 17$ \\
Number (\%) receiving antenatal maternal dexamethasone & $17(16 \cdot 7)$ & $11(13 \cdot 4)$ & $0 \cdot 68$ \\
Number (\%) of neonates with a pneumothorax requiring drainage & $6(5 \cdot 9)$ & $8(9 \cdot 8)$ & $0 \cdot 41$ \\
Number (\%) born in teaching hospital & $75(73 \cdot 5)$ & $66(80 \cdot 5)$ & $0 \cdot 30$ \\
\hline
\end{tabular}

Table 3 Main fundal abnormalities in ten 2-year-old children with cicatricial retinopathy of prematurity, according to gestational age at birth and treatment with cryotherapy

\begin{tabular}{|c|c|c|c|}
\hline $\begin{array}{l}\text { Gestational } \\
\text { age (weeks) }\end{array}$ & Cryotherapy & Right fundus & Left fundus \\
\hline $\begin{array}{l}\text { A Prophylac } \\
23 \cdot 0 \\
23 \cdot 7 \\
24 \cdot 6 \\
27 \cdot 3\end{array}$ & $\begin{array}{l}\text { tic surfactant g } \\
\mathrm{NC} \\
\mathrm{R}+\mathrm{L} \\
\mathrm{R}+\mathrm{L} \\
\mathrm{R}+\mathrm{L}\end{array}$ & $\begin{array}{l}\text { Pup } \\
\text { Peripheral } R D+\text { macular pigmentation } \\
\text { Normal } \\
\text { Normal } \\
\text { Vessel traction }\end{array}$ & $\begin{array}{l}\text { Traction + macular ectopia } \\
\text { Vessel traction } \\
\text { Traction }+ \text { macular ectopia } \\
\text { Vessel traction }\end{array}$ \\
\hline $\begin{array}{l}\text { B Rescue su } \\
24 \cdot 4 \\
24 \cdot 7 \\
25 \cdot 0 \\
27 \cdot 1 \\
27 \cdot 7 \\
28 \cdot 0\end{array}$ & $\begin{array}{l}\text { factant group } \\
\text { NK } \\
R+L \\
R+L \\
R+L \\
R+L \\
N C\end{array}$ & $\begin{array}{l}\text { Vessel traction + tilted disc } \\
\text { Vessel traction + tilted disc } \\
\text { Normal } \\
\text { Vessel traction } \\
\text { Subtotal RD including macula } \\
\text { Traction + macular ectopia }\end{array}$ & $\begin{array}{l}\text { Normal } \\
\text { Tilted disc } \\
\text { Vessel traction } \\
\text { Vessel traction } \\
\text { Funnel RD } \\
\text { Traction+macular ectopia }\end{array}$ \\
\hline
\end{tabular}

$\mathrm{NC}=$ no cryotherapy as threshold not reached; $R=$ right eye, $\mathrm{L}=$ left eye; $\mathrm{NK}=$ not known; $\mathbf{R D}=$ retinal detachment.

groups are shown in Figure 1. Of neonates born at 23 weeks' gestation receiving prophylactic surfactant, two out of the three survivors developed cicatricial ROP. No neonates born at 23 weeks' gestation survived in the group receiving rescue surfactant. However, despite increased survival in the group receiving prophylactic surfactant, there was no overall increase in the incidence of cicatricial ROP as there was a decreased incidence of cicatricial ROP in those over 23 weeks' gestation (prophylactic surfactant $2 / 97,2 \cdot 1 \%$, rescue surfactant $6 / 81,7 \cdot 4 \%$, not significant, $\mathrm{p}=0 \cdot 18$ )

Unfortunately, screening for acute ROP was not comprehensive and no screening data could be found in the records of 40 neonates.
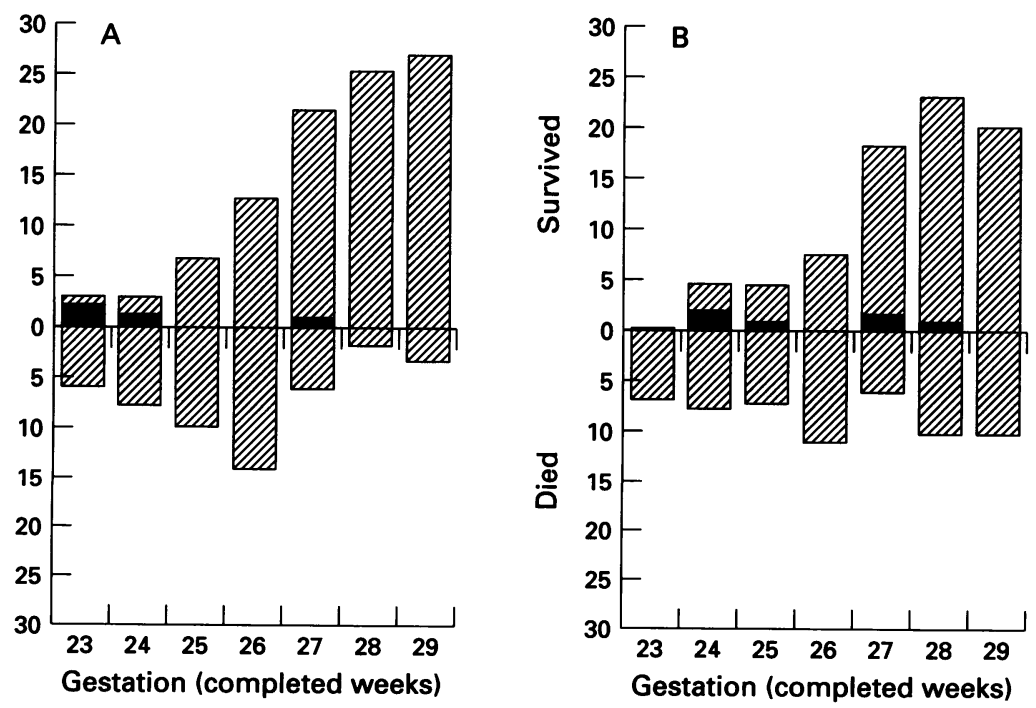

\section{ROP}

Figure 1 Deaths and 2 year survivors in children born at less than 30 weeks' gestation treated with $(A)$ prophylactic or $(B)$ rescue surfactant as required. Children developing cicatricial retinopathy of prematurity (ROP) are indicated according to gestational age at birth.
(These neonates consisted of 18 in the prophylactic and 22 in the rescue surfactant group. There was no statistically significant difference in the mean gestational age at birth of the neonates in these two groups: mean 28.44 and $28 \cdot 40$ weeks respectively, $p=0.91$.) The worst stage of acute ROP for the two groups is shown in Table 4. There was no significant difference between the two groups in the worst stage of acute ROP seen or in the number of screening examinations (prophylactic group 2.0 examinations/neonate screened and rescue group $2 \cdot 1$ examinations/neonate screened).

\section{Discussion}

Studies of ROP after rescue surfactant treatment for severe RDS compared with controls receiving no surfactant have been more difficult to interpret than studies of prophylactic surfactant. This is because historical controls ${ }^{10}$ or the use of neonates with less severe RDS as controls $^{11}$ are not necessarily comparable.

Previous studies of the effect of prophylactic surfactant on acute ROP have looked at small numbers but are consistent with this study. ${ }^{12-14}$ Holmes et al showed no effect of prophylactic surfactant on the incidence of ROP in 23 neonates compared with controls. Repka et al showed a decreased incidence of ROP after prophylactic surfactant compared with historical controls ${ }^{13}$ and no effect when contemporary controls were used. ${ }^{14}$ However, this latter study excluded the smallest babies who would be expected to have the highest incidence of ROP and therefore be the most likely to reveal any effect prophylactic surfactant may have had.

In our study, data from routine screening for acute ROP were not complete. ${ }^{15}$ This prevented proper statistical analysis but the data available are consistent with the results for cicatricial ROP. Thus, there was no significant difference between the two groups in the worst stage of acute ROP reached, with a trend for increased numbers without ROP in the prophylactic surfactant group. Bias

Table 4 Worst stage of acute retinopathy of prematurity (ROP) reached by neonates receiving prophylactic or rescue surfactant

\begin{tabular}{lll}
\hline $\begin{array}{l}\text { Worst stage of } \\
\text { acute ROP }\end{array}$ & $\begin{array}{l}\text { Prophylactic } \\
\text { surfactant group } \\
\text { (number of neonates) } \\
(n=100)\end{array}$ & $\begin{array}{l}\text { Rescue } \\
\text { surfactant group } \\
\text { (number of neonates) } \\
(n=81)\end{array}$ \\
\hline Not screened & 18 & 22 \\
Stage 0 & 55 & 38 \\
Stage 1 & 9 & 8 \\
Stage 2 & 6 & 5 \\
Stage 3 & 2 & 0 \\
Stage 3 threshold & 7 & 7 \\
Unknown stage & 3 & 1 \\
\hline
\end{tabular}


towards increased identification of acute ROP in the rescue group owing to a longer hospital stay seems unlikely as there was no significant difference in the number of screening examinations in the two groups. Bias due to easier examinations in less sick neonates is possible but would tend to identify more ROP in the prophylactic surfactant group and reduce any possible protective effect of prophylactic surfactant on development of severe ROP.

This study has larger numbers than previous studies and is based on gestational age rather than birth weight, which has a closer correlation with the incidence of ROP. ${ }^{5-7}$ Nevertheless, the numbers with cicatricial ROP were not high enough to draw firm statistical conclusions. These results show a trend towards a reduction in gestational age-adjusted incidence of cicatricial ROP. If this trend is truly representative, then to have an $80 \%$ chance of demonstrating a significant difference $(p=0.05)$ between the groups, it would have been necessary to examine 1400 children. The OSIRIS trial ${ }^{8}$ showed that prophylactic surfactant given to very premature neonates resulted in a $16 \%$ reduction in death or oxygen dependence at term $(p=0.001)$ so such a study would be unethical. Thus, in the absence of further data, the following observations can be made which may offer some clues for future study.

The incidence of cicatricial ROP seems to be related to both gestational age and respiratory health of neonates. The survival of some neonates born at 23 weeks in the group receiving prophylactic surfactant was associated with a high incidence of cicatricial ROP (two of three survivors). As no babies born at 23 weeks survived in the rescue surfactant group, this is consistent with the hypothesis that ROP is related to gestational age and that factors improving survival increase the incidence of ROP.

The incidence of cicatricial ROP in all other children (born 24-29 weeks) was three times higher in the rescue surfactant group, although this did not reach statistical significance. This suggests that factors other than gestational age are important in the aetiology of ROP as prophylactic surfactant may protect against the development of severe ROP. Interestingly, the mechanism of this protection may be related to events occurring soon after birth. In the multicentre trial of prophylactic surfactant, ${ }^{8} 75 \%$ of neonates in the rescue surfactant group developed severe RDS and therefore received rescue surfactant at a mean of only 1 hour later than the prophylactic surfactant group (mean age of 180 minutes compared with 118 minutes).

The importance of early events in the pathogenesis of ROP is supported by Prendiville and Schulenburg 5 who showed a significant correlation between the development of severe acute ROP (stage 3 and 4) and three independent factors (acidosis, partial pressure of arterial oxygen $\left(\mathrm{PaO}_{2}\right)>12 \mathrm{kPa}$, and pneumothorax) occurring before the onset of the demarcation line. In contrast, there was no difference in the exposure to any of their 34 risk factors between those neonates with mild (stage 1 and 2) and those with advanced (stage 3 and 4) acute ROP after the appearance of the demarcation line. 5

Administration of natural surfactant results in a rapid increase in $\mathrm{PaO}_{2}$ with marked hyperoxia occurring within 5 minutes. ${ }^{3}$ The increase in $\mathrm{PaO}_{2}$ is less rapid after administration of synthetic surfactant ${ }^{16}$ such as Exosurf, but nevertheless there may be a period of instability with hyperoxia. All neonates in the rescue group who received surfactant had developed severe RDS. Therefore they would be expected to have had higher inspiratory oxygen requirements and ventilator pressures before surfactant treatment and greater fluctuations in $\mathrm{PaO}_{2}$ as a result of surfactant administration. There was also a higher incidence of pulmonary air leaks/pneumothoraces in the rescue surfactant group which may result in further fluctuations in $\mathrm{PaO}_{2}$.

Flynn et al ${ }^{17}$ also noted that $\mathrm{PaO}_{2}$ fluctuated over long periods in ventilated premature neonates despite transcutaneous oxygen monitoring and active control of inspired oxygen to avoid hyperoxia during study conditions. The time on the ventilator has been inversely related to the incidence of ROP. ${ }^{6}$ Premature neonates receiving prophylactic surfactant spent less time on the ventilator and this may be related to the effect of prophylactic surfactant on the incidence of cicatricial ROP.

In summary, although this study cannot draw any firm statistical conclusions it does suggest that improved survival does not necessarily result in an increased incidence of cicatricial ROP. Indeed, there may be further scope to improve the risk of ROP in very premature neonates by factors which affect respiratory health and physiological stability during the early neonatal period.

We are grateful to $\mathrm{Mr}$ John Dutton for statistical assistance and to the medical and nursing staff of the Northern Neonatal Network, who cared for the neonates in this study.

1 Valentine PH, Jackson JC, Kalina RE, Woodrum DE. Increased survival of low birth weight infants: impact on the incidence of retinopathy of prematurity. Pediatrics the incidence of

2 Long W, Corbet A, Cotton R, Courtney S, McGuiness G, Walter $\mathrm{D}$, et al. A controlled trial of synthetic surfactant in infants weighing $1250 \mathrm{~g}$ or more with respiratory distress syndrome. N Engl $\mathcal{F}$ Med 1991; 325: 1696-703.

3 Collaborative European Multicenter Study Group. Surfactant replacement therapy for severe neonatal respiratory distress syndrome: an international randomized piratory distress syndrome: an international
clinical trial. Pediatrics 1988; 82: 683-91.

$4 \mathrm{Ng} \mathrm{YK}$, Fielder AR, Shaw DE, Levene MI. Epidemiology of retinopathy of prematurity. Lancet 1988; ii: 1235-8.

5 Prendiville A, Schulenburg WE. Clinical factors associated with retinopathy of prematurity. Arch Dis Child 1988; 63: 522-7.

6 Gunn TR, Easdown J, Outerbridge EW, Arande JV. Risk factors in retrolental fibroplasia. Pediatrics 1980; 65: 1096-100.

7 Holmstrom G, el Azazi M, Jacobson L, Lennerstrand G. A population based, prospective study of the development of ROP in prematurely born children in the Stockholm area of Sweden. Br f Ophthalmol 1993; 77: 417-23.

8 The OSIRIS Collaborative Group (open study of infants at high risk of or with respiratory insufficiency - the role of surfactant). Early versus delayed neonatal administration of a synthetic surfactant - the judgement of OSIRIS. of a synthetic surfactant

9 International Committee. An international classification of retinopathy of prematurity. Br $\mathcal{J}$ Ophthalmol 1984; 68: 690-7.

10 Termote JUM, Schalij-Delfos NE, Wittebol-Post D, Brouwers HAA, Hoogervorst BR, Cats BP. Surfactant replacement therapy: a new risk factor in developing retinopathy of prematurity? Eur $\mathcal{f}$ Pediatr 1994; 153: 113-6.

11 Rankin SJA, Tubman TRJ, Halliday GL, Johnston SS. 
Retinopathy of prematurity in surfactant treated infants. Brf Ophthalmol 1992; 76: 202-4.

12 Holmes JM, Cronin CM, Squires P, Myers TF Randomised clinical trial of surfactant prophylaxis in retinopathy of prematurity. $\mathcal{f}$ Pediatr Ophthalmol Strabismus 1994; 31:189-91.

13 Repka MX, Hudak ML, Parsa CF, Tielsch JM. Calf lung surfactant extract prophylaxis and retinopathy of premasurfactant extract prophylaxis and retin.

14 Repka MX, Hardy RJ, Phelps DL, Summers G. Surfactant prophylaxis and retinopathy of prematurity. Arch Ophthalmol 1993; 111: 618-20.
15 Trainor S, White GL, Trunnell E, Kivlin JD. Compliance with a standard of care for retinopathy of prematurity in one neonatal intensive care unit. $f$ Pediatr Ophthalmol Strabismus 1988; 25: 237-9.

16 Morley CJ, Greenough A. Respiratory compliance in premature babies treated with artificial surfactant (ALEC). Arch Dis Child 1991; 66: 467-71.

17 Flynn JT, Bancalari E, Snyder ES, Goldberg RN, Feuer W, $\mathrm{T}$, Bancalari E, Snyder ES, Goldberg RN, Feuer , Cassady J, et al. A cohort study of transcutaneous retinopathy of prematurity. $N \mathrm{Engl} f \mathrm{~J}$ Med 1992; retinopathy $1050-4$. 